\title{
CODE OF ETHICS FOR PUBLICATION IN SCRIPTA SCIENTIFICA MEDICA
}

\author{
Albena Kerekovska ${ }^{1}$, Bistra Galunska ${ }^{2}$, Zhaneta Radkova ${ }^{3}$ \\ ${ }^{1}$ Department of Social Medicine and Public Health Organization, Faculty of Public \\ Health, ${ }^{2}$ Department of Pharmaceutical Sciences, Faculty of Pharmacy, ${ }^{3}$ Library and \\ Information Service, Medical University of Varna
}

\begin{abstract}
The manuscript presents the Code of Ethics for issue and publication in „Scripta Scientifica Medica”, an official scientific publication of Medical University "Professor Paraskev Stoyanov" of Varna. Its formulation is based on ethical principles established in internationally recognized requirements of scientific organizations and international committees. In the context of a global move towards scientific and research integrity, conformity to internationally acknowledged standards of good publication practice is a must for a modern refereed scientific journal. The ethical principles in the Code of publication ethics underlie the duties and responsibilities of the publishing authors, the journal editors and the reviewers of the proposed manuscripts.
\end{abstract}

Key words: publication ethics, biomedical research, Scripta Scientifica Medica, Medical University of Varna

\section{INTRODUCTION}

The Code of Ethics for publication in Scripta Scientifica Medica, the official scientific publication of Medical University "Professor Paraskev Stoyanov" of Varna, is based on ethical principles established in internationally recognized requirements of scientific organizations and international committees: Committee on Publication Ethics; International Committee of Medical Journal Editors; Council of International Organizations for Medical Sciences; World Association of Medical Editors; World Medical Association, etc. (1-6). The ethical standards of publication in Scripta Scientifica Medica are

Address for correspondence:

Albena Kerekovska, MD, PhD

Department of Social Medicine and Public Health

Organization, Faculty of Public Health,

Medical University of Varna,

55 Marin Drinov Str., 9002 Varna, Bulgaria

E-mail: kerekovska_a@yahoo.com

Received: November 27, 2012

Accepted: January 15, 2013 adopted by the institutional Committee on Research Ethics at the Medical University of Varna.

Conformity to internationally acknowledged standards of good publication practice is a must for a modern refereed scientific journal.

\section{Code of Ethics for publication in Scripta Scientifica Medica}

The ethical principles in the Code are generally focused on the duties and responsibilities of the publishing authors, the journal editors and the reviewers of the proposed manuscripts.

Duties and responsibilities of the authors publishing in the journal

Requirements of objectivity and truth

The authors of a publication have to present the accomplished work on the research, the actual results and their objective discussion accurately, reliably and objectively. Any kind of modification, omission and/ 
or intentional misinterpretation of the data such as falsification and fabrication is ethically unacceptable. Any manipulation of the results and intentional publication of incorrect conclusions in order to support or prove the author's thesis is inadmissible.

\section{Originality, plagiarism, citation}

Authors have to ensure that the original publication proposed for publishing has been developed by them. It should contain sufficient detailed description of the experimental part, as well as citations related to it and allowing its full reproduction. Plagiarism in any kind of form (misuse of a name, copying or paraphrase) of which authors bear personal responsibility is inadmissible, unethical and unacceptable. In case of using results or a text taken from of other authors' publications, they have to be cited accurately and properly.

While using someone else's unpublished data, the author has to have requested (and have been granted) a written permission by the author of the study or/and the copyright holder of the respective result. If the permission is obtained, the citation has to be specific. Information obtained in an informal way such as in conversations, by correspondence, discussions and in the course of confidential activities (reviewing articles, applications for project funding) is impermissible to be used or reported without explicit written permission.

\section{Access to the original data}

Authors have to provide access to the primary original data should they be requested by the Editorial board of the journal.

\section{Multiple and simultaneous publication}

It is contrary to the ethical principles to submit a manuscript that has already been published in another journal or it has been submitted for a review awaiting a decision on its publication. It is inadmissible to submit materials which replicate extracts of already published articles or the unnecessary 'fragmentation' of publications. Authors declare that the research materials have not been published before in a written or electronic form, they have not been proposed and will not be offered for publication to another journal during their consideration in Scripta Scientifica Medica until the final decision on publication of the
Editorial board. Provided that there is an overlap with an already published article, including use of the same themes and repetition of data, this article should be cited entirely.

\section{Acknowledgement, funding and sponsorship}

It is in accordance with the ethical principles of publication to express gratitude to the rest of the participants in the study for their assistance, to people who have intellectual contribution or have rendered technical, organizational, material or financial assistance. All the people who have contributed to the development of the material but they do not meet the criteria for authorship should be mentioned in the acknowledgement paragraph. Acknowledgement is expressed to colleagues, reviewers and editors for valuable suggestions or provided real help for the improvement of the work. Special gratitude is due to colleagues who have presented the author with results of their own published or unpublished studies.

All sources of funding have to be declared as an acknowledgement at the end of the text. It is obligatory to mention the projects and grants which have received funding for research. Authors should declare the role of the sponsors in the study.

\section{Copyright}

Anyabuserelated todetermination of theauthor's status is ethically unacceptable. The recognition of authorship is based on the direct participation and substantial intellectual contribution to the research and determines the full responsibility for the content of the published manuscript of each co-author.

Attribution of co-authorship to a person without any real creative participation (intrusive or 'honorary' authorship) as well as non-recognition of deserved co-authorship and understatement of due recognition of essential contribution are serious violations of the author's best practice. Only people who have a significant contribution to the development of the conception, to the design and conduct of the study, data collection, receipt, analysis and interpretation of the results as well as to the writing and the critical revision of the manuscript, and who have given their consent to its publication are mentioned as co-authors. 
People who render only organizational, technical, financial, methodological help or any other help or assistance but they do not participate in the actual process of creation are not co-authors. The support of other units and individuals as well as members of the management of the scientific organization is noted in a remark expressing gratitude but they are not included in the list of co-authors.

It is unethical for a person who has sponsored the publication of scientific work or the research leader who has accomplished the scientific guidance while it has been written to claim authorship if they have not participated throughout the actual process of creation.

The order of the authors is a decision made together by the team of authors at the very beginning of the study. In joint research and investigation it is ethical to determine the actual contribution of each researcher according to the work accomplished by him/her.

Any kind of intellectual exploitation is inadmissible regardless of the relationships between the co-authors and the administrative or academic position they have.

It is not allowed unpublished materials of the team to be presented as personal research without the consent of the other members of the team.

The corresponding author has to ensure the inclusion of all co-authors and contributors to the manuscript. He/she has to ensure that the co-authors have adopted the final version of the article and have agreed with its submission for publication. Authors bear responsibility for the content of the publications as well as for the personal contribution of the included co-authors.

The authors complete a declaration that they have not violated the principles of Copyright Law and the study has been approved by the Committee on Research Ethics.

The copyright of the published scientific papers in the journal is granted fully and forever to the publisher of Scripta Scientifica Medica (Medical University of Varna).

\section{Ethical aspects of research on humans and experimental animals}

The presented materials and the research described in them have to conform to the ethical standards of human studies and experiments with laboratory animals. Reports on the results of experimental studies involving humans or animals must contain a written confirmation that the requirements of the relevant official documents in this area are strictly observed.

The publication of research involving human subjects requires confirmation that the study has been approved by the relevant Committee on Research Ethics of the institution in which it is conducted and that the participants in the study have given their written informed consent to be included in it. Patients with their names, initials, or photos which can identify them should not be mentioned.

In publication of studies with experiments on laboratory animals it is necessary to confirm that the care taken of them is in compliance with the relevant requirements and prior authorization to conduct experiments is received by the relevant Committee on Ethics on animal experiments.

\section{Conflict of interest}

Each author is required to report financial or personal relationship (if any) with other persons or organizations, the presence of which could cause incorrect presentation/distortion of the survey results and their interpretation. Examples of potential conflicts of interest are: recruitment, consultancy, fees, paid expert recommendations, patent registration, supply of materials, grants or any other funding. Accidental participants in the research, interventions in the experiments, a conflict of interest between the authors of the publication are not allowed. Publication or use of a part of the material without prior consent of the other coauthors is unacceptable.

\section{Errors in publishing and corrections}

The author should agree with all the coauthors on correction recommendations made by the reviewers and the Editorial board. If major errors or inaccuracies in published work are found out, the author should timely notify the journal editor or the publisher of amendment. If the editor or the 
publisher obtains information about an essential error from a third party, it is the responsibility of the author to correct the error or to provide evidence of the correctness of the original article.

\section{Duties and responsibilities of the journal editors}

\section{Reasons for publication}

The proposed research materials are published only after being reviewed and approved by the editorial board of the journal. The editorial staff of the journal supports the principle of 'editorial freedom and independence' for non-interference by the publisher in regard to the thematic selection and publication decisions. The editors of the journal are responsible for deciding on the publication of a certain scientific work. In the process of making a decision on publication the editors consult with the members of the editorial board and the reviewers.

The decision should be a result of the compliance of the work of the criteria for publication in the journal and its aims and scope. The underlying criterion for publication of submitted materials is the importance to the development of scientific knowledge and the academic contribution to the field of science rather than the career development of the publishing author. The journal editors are obliged to avoid publishing meaningless, redundant or irrelevant to the pre-established criteria publications.

It is the obligation of the editorial board to organize a prompt review and to deal with the author's work as quickly as possible, to make a clear statement and notify the author as soon as possible. The editorial board is called upon to draw the final conclusion on the merits and demerits of a given manuscript. It has an obligation to help the author to present the results of his/her research in the best way so that the work should be most useful to the scientific community.

The editorial board is required to notify the author of all the weaknesses and errors without the removal and repair of which the article will not be published. These include technical faults and factual and methodological errors, incorrect, insufficient or unethical citation, etc. The editors are obliged to ensure that any published materials are evaluated in advance by reviewers with appropriate qualifications and competence in regard to the issue being reviewed.

\section{Objectivity}

The editors evaluate the material submitted for publication objectively without being influenced by gender, sexual orientation, religious beliefs, ethnic origin, nationality, political affiliation, administrative or academic position of the authors. The editorial board provides diverse affiliations of the publishing authors and assessing reviewers as well.

\section{Transparency and sustainability}

The journal follows a transparent editing policy. The editors are obliged to develop, validate, update systematically and promote the publication criteria, the requirements to authors and the guidelines on reviewing the submitted manuscripts. The editors are obliged to seek feedback from authors, readers and reviewers actively in order to improve the editing process. It is the responsibility of the editorial board to support initiatives preventing abuse in scientific publishing and authorship and to combat plagiarism.

\section{Confidentiality}

The editors can distribute information related to a material submitted for publication only to the corresponding author, reviewers, potential reviewers, and if necessary to the publisher. Ideas or information acquired in the process of evaluation of this material are strictly confidential and can't be used for personal benefits. The publication of reviews or comments on the submitted material before its publication without the prior consent of the authors and reviewers is unacceptable.

\section{Conflict of interest}

Unpublished information disclosed in the submitted manuscript can't be used by the editors for their research without the explicit written consent of the author. The editors must refuse to take into consideration manuscripts in which they have a conflict of interest resulting from competitive, collaborative, or other relations with any of the authors, sponsors or the institutions associated with the publication. The editors have to require all the assistants to promptly disclose competing interests 
and they have to publish corrections if such interests are proved after the publication.

The process of receiving, examining and reviewing the sponsored applications of the journal is based on their scientific merit and it is not influenced by commercial factors.

Those sections of the journal which are not subject to review must be specified clearly.

\section{Self-citation of the journal}

It is unacceptable for the editor to require the authors to cite the journal and to stipulate this before accepting the publication. The recommendations for references to other articles have to be based on a direct connection with the material submitted for publication aiming at further development of the research and scientific knowledge. The editor can direct the author to appropriate literature without exceeding the formal requirements of citation of certain journals.

\section{Complaints}

The editor is obliged to take appropriate action when there are filed complaints concerning the ethical aspects related to a submitted manuscript or an already published article. This includes contacting the author of the article and detailed consideration of the filed complaint. When a complaint is upheld, it is advisable to publish corrections, to give an opinion, disclaimer, etc.

\section{Duties and responsibilities of the journal reviewers}

\section{Supporting editorial decisions}

Reviewing is a key part of the communication in the scientific society and an essential element of the scientific method. The reviewing of a scientific paper helps not only the author to improve the quality of his/her manuscript but also the editorial process and the process of making a decision on publication.

\section{Correctness in terms of adequate qualification}

The reviewer has to be a highly competent scientist in the relevant sphere of science. He/ she is obliged to notify the editor when he/she is inadequately qualified to review a particular scientific material or he/she is incapable of making an adequately accurate review. It is unacceptable the review to be delayed provided there is a commitment on the part of the reviewer.

\section{Confidentiality}

Each article that is subject to reviewing should be considered a confidential document. It is unacceptable the article to be discussed or disclosed to any third parties except in cases when they have been authorized by the journal editor.

\section{Objectivity}

The reviewer is obliged to evaluate the submitted manuscript objectively, he/she should not be influenced by personal biases and relationships with the author of the reviewed work. The reviewer expresses his/her opinion clearly and supports it with objective arguments and constructive criticism. Personal criticism and personal attacks against the author on the part of the reviewer are unacceptable.

\section{Accuracy of citations}

The reviewer is required to ensure the accuracy of citations. He/she must promptly notify the editor in case of incorrect citation or noted duplication of parts of the material of an already published article.

\section{Conflict of interest}

It is unacceptable unpublished materials in a manuscript submitted for a review to be used by the reviewer in his/her own research without the explicit written consent of the author.

Ideas and information acquired in the process of reviewing are strictly confidential and can't be used for personal benefits.

It is unacceptable for the reviewer to accept to review an article in case he/she has established cooperation or any other relationships with members of the team of authors or institutions associated with the submitted material which could influence the objective evaluation of the work.

\section{REFERENCES}

1. Committee on Publication Ethics. Guidelines on good publication practice (COPE). 1999.

2. Elsevier. Publishing ethics resource kit (PERK). http://www.elsevier.com/wps/find/editorshome. editors/. 
3. Elsevier. Ethical guidelines for journal publication. www.elsevier.com/ethicalguidelines.

4. International Committee of Medical Journal Editors. Uniform requirements for manuscripts submitted to biomedical journals: publishing and editorial issues related to publication in biomedical journals. http://www.icmje.org/publishing.html.

5. Council of Science Editors. CSE's White Paper on promoting integrity in scientific journal publications, 2012 Update. 3rd revised ed. Wheat Ridge, CO, 2012. http://www.councilscienceeditors. org/files/public/entire_whitepaper.pdf.

6. World Medical Association. The code of ethics of the World Medical Association (Declaration of Helsinki) www.wma.net/ en/30publications/10policies/b3/index.html.
Acknowledgements: The authors would like to acknowledge the expertise support of all members of the Research Ethics Committee at Medical University of Varna. Their critical appraisal and devoted cooperation was essential for the formulation and adoption of the Code of Publication Ethics of Scripta Scientifica Medica. 